\title{
Evaluation Strategies for Effective Teaching and Learning Processes in Schools
}

\author{
Adikwu E. Godwin
}

\author{
Department of Technical Education, College of Science and Technology, Hassan Usman Katsina Polytechnic Katsina
}

\section{Doi:10.5901/jesr.2014.v4n7p96}

\section{Abstract}

The Nigerian Primary education curriculum places enormous responsibilities on the teacher in the sense that during the course his interaction with, and instruction of the child in the school, he is expected to focus his activities on the ultimate attainment of the set objectives for that level of education. The effective teacher must from time to time pose and attempt to answer questions related to his activities in the instructional process, the response of the pupil to his lessons, the effectiveness of his techniques and the instructional material.

\section{Introduction}

Evaluation is a very important and essential component of the teaching learning process. It assists the teacher in determining the effectiveness of his teaching, the quality of learning and the progress of the child. It provides the teacher with the necessary information for predicting the area where the child could be successful in future and guiding him accordingly (Ismaila, 2003).

It is a means by which the school reports on the child to his parents and sponsors and to Education authorities. Above all the teacher should be able to answer those questions posed and also use the answers to improve his teaching in the process of posing questions relating to his lessons, his pupils and the instructional materials, he is involving himself in some form of evaluation, that is gathering information on the basis of which to make some judgments and to take certain decisions that could improve learning in his pupils.

In essence this paper focuses on discussing how-evaluation can be effectively used in the primary school to improve the quality of teaching and learning.

\section{Concept of Evaluation}

Makama (2005) attempted to clear the air on preserved confusion in understanding the differences between Measurement, testing and evaluation, in the educational circles, where he felt to some extent that some teachers are of the opinion that they are interchangeable and as such mean the same thing. He revealed that testing is a process of gathering data and Measurement is a method in which the gathered data is compared with the set standard (quantity). Evaluation therefore deals with the quality as such helps a classroom teacher to make decisions concerning the classroom instruction.

In its most simple form to evaluate is to place a value upon or judge in education that usually means judging a student, a teacher or an educational programme. Teachers make numerous judgments in the process of evaluating the educational achievement of their students. Educational evaluation could be defined as a process of making judgments which must be make in order for education to work (Ismaila, 2003). Education as a process involves many activitiesnumber of steps. When we want to make any judgement we need to identify and locate the information that would assist us. When the information becomes available it becomes necessary to interpret it.

As a result of these series of activities involved in the process of evaluation we can also define it as the process of obtaining information and using it to make judgement. It is generally believed that when a judgement is made it is usually used to influence the outcome of some decisions. That Philip is a slow reader may be used to help him decide what reading group to place Philip in. It may also help the teacher in his decision about the kinds of materials to assign Philip in his work. Furthermore it may be used in making decisions about how much independent work should be assigned to Philip.

On the basis of this additional information that evaluation plays a role in decision making, we can again define evaluation as the process of obtaining information and using it to form judgments which in turn are to be used in decision 
making. Educational decisions are made on the basis of judgments and judgments, in turn are made on the basis of information. The interdependence of these three concepts (decisions, judgments and information) essentially defines evaluation.

Okoro (1991) there defined Evaluation as the appraisal of the worth or value of a thing or action and the making of appropriate decision on the basis of such appraisal and he further sees evaluation in education as the collection of data and the use of such data to assess the effectiveness or quality of a programme or performance.

\section{Why do we Assess Pupils Learning}

Teaching and Learning constitute a process that involves interacting parties. The two parties are the teacher and the learner. What one does impacts on the other. As the teacher teaches, the learner learns. In this process of interaction, it is important for both parties to determine whether they are working together in harmony towards the same goal (Ismaila, 2003).

The goal is that the pupils should learn and that learning should be manifested in change in pupil behavior. It is the responsibility of the teacher as the guide in the teaching/learning process to determine from time to time whether the learner is responding in desired ways to his instruction. The parents and education authorities are also interested in knowing how well the teacher is performing his duties and whether his performance is influencing the pupils behavior. The child in school is aware that he is there to learn. It would be of interest to him to know what progress he is making in the course of learning. The teacher uses a variety of materials and strategies to teach. The effectiveness of these strategies a material can be only be measured in terms of how they facilitate learning (Okoro, 1991). This means that evaluation does not only focus on the learner, it also focuses on what the teacher does and how he does them.

Evaluation in the school is essential because it assists the teacher to determine how to improve his teaching so that learning can take place.

\section{Purpose of Evaluation in the school}

a) Diagnosis: It is used for finding out what is happening in response to the teaching. This may be at the level of the individual learner or the group. Sometimes all is well and no immediate action is necessary, sometimes all is not well and remedial action of some kind is required, for example additional instruction or a new book.

b) Evaluation: It is concerned with judging the worth or value of something. In the evaluation of course materials, teaching strategies, curricular, organizational patterns, institutions and the like, the assessment of those being taught will provide important evidence of the effectiveness of the teaching-hence pupil assessment usually forms an essential component of evaluation.

c) Guidance: This refers to helping to make more relevant, more appropriate choices or decisions, for example in career guidance and subject or course choice. The assessment must therefore be as relevant as possible to all those different options, providing a kind of information bank which all those giving the guidance can draw on as appropriate (Iwuji, 1990). The above three purposes of evaluation are generally concerned with using information for remedial action of some kind: to assist the individual teacher, to improve the quality of instruction, or the quality materials or course design, etc.

The next three purposes are more concerned with aiding institutional policies. If the school is selecting pupils for a new course with a limited number of places available grading becomes much more necessary.

d) Grading: This refers to assigning to individuals a number or a letter signifying to individuals a number or a letter signifying a 'standard' they have achieved. This may be tied to objective criteria concerning levels of performance or simply reflect an 'order of merit'. In either case, in the interest of fairness, we need to devise assessment which is as sensitive as possible to differences between individuals.

e) Selection: This is when we need to choose individuals for a particular job or course of study or class or university. Usually, we want to make sure that we select those who are the most suitable and will be most likely to benefit. In consequence we devise assessment to provide us with relevant information. In any process of selection it is obviously helpful to have an idea of how people are likely to perform in the future.

f) Prediction: This involves projecting into the future how a particular child is likely to perform in the future. Will a particular individual, for example, be suited to a career as a doctor or make a good airline pilot? Evaluation helps in predicting future success. The concern here thus lies with potential rather than with past achievement. Evaluation, therefore, needs to be devised which will identify that potential and hence predict. 
The more accurate this prediction the less wastage there will be in the subsequent training, i.e. those selected will be the ones most likely to benefit.

While these categories of purpose of evaluation have been treated separately it is important to mention that they are interdependent and overlap considerably. Guidance and diagnosis, for example, are often difficult to separate. Pupils are often graded in order that others can more readily select. It is also important to note that different purposes to some extent demand different techniques of evaluation for their realization and require information about different aspects of the individual being evaluated. When grading pupils, for example, the main evidence used is likely to be past achievement measured in relation to a particular topic or subject. When selecting for a future course of study, we may be primarily interested in an individual's potential expressed through mastery of relevant skills or through a measure of his or her general ability. (LSPEB 1994)

\section{Strategies For Evaluating Teaching and Learning}

It has earlier been mentioned that different types (or categories) of learning lend themselves to some certain specific instruments when it comes to evaluation. What particular instrument we use depends on a number of factors like:

* The information we are looking for.

* The learning objectives we want to assess.

* Appropriateness of the instrument.

* Reliability of the instrument.

* Validity of the instrument. That is, will the same instrument give the sameresult under the same conditions? evaluation.

These and many more factors need to be considered while deciding on the kind of instrument to use for

following are the commonest instruments that can be used to gather information for educational evaluation: Tests, Interviews, Questionnaire, Projects, Observation, Checklists, and Rating Skills Sociometry.

1. Testing Technique: Tests are generally quite effective for evaluating the cognitive domain. There are different types of tests, like Essay, Short Answer or Restricted Response type (list the parts of......), Extended Response type (Give an account of....), Objectives. Whichever test type is selected for use it is important that adequate planning should be done. Before deciding to use a test for assessment the teacher should consider the following questions the answers to which would equip him well for his testing.

a) What is the function of the test?

b) What objective is the teacher trying to achieve in the area covered by the test?

c) What content has been dealt with in the field covered by the test.

d) How much emphasis has been given to each topic?

e) What type of test exercise will best provide evidence on the achievement of those objectives identified?

There are some basic things to put into consideration using any type of testing technique. One of these is to develop a full statement of objectives for the course or unit. Instructional objectives should be stated in terms of pupil's behavior and not in terms of learning activities or teacher's purpose. They should contain an action verb that indicates the behavior that the pupil should show in dealing with content. They should be realistic and achievable. They should also be appropriate to the levels of learning that we want to assess (knowledge, comprehension, application, analysis, synthesis and evaluation)

2. Interview: It is possible to obtain from an individual or a group of persons for the purpose of evaluation by having direct discussion with him or them. Information so obtained may be about the person or persons with whom the interview is held or about an event or about a third party. An interview can be structured or unstructured. The strength of the interview technique is in the face-to-face contact between the interviewer and the interviewee. In conducting interviews the following should be noted:

a) Specify objective of interview and prepare lead questions;

b) Create a conducive environment.

c) Probe answers by using occasional guide questions.

d) Take note of responses and if possible record the interview with interviewee's consent.

e) Cross-check information given by interviewee.

f) Avoid being hostile and impatient.

g) Appreciate the cooperation of the interviewee at the end of the encounter (Ohuche, 1990).

3. Questionnaire. The questionnaire is useful for collecting information on interests, attitudes, social, physical, 
and other adjustment of pupils. There are open questionnaires and those that provide range of responses or alternate questionnaire. In constructing a questionnaire take note of the following guidelines:
a) Determine what you want to measure and identify the components;
b) Construct enough items to measure the different components identifies;
c) State each item clearly, precisely and avoid ambiguity;
d) Provide very clear instructions;
e) The questionnaire should be moderate in length.

4. Checklist:A checklist is one of the instruments used for observational evaluation. A checklist assesses the existence or non-existence of a specific characteristic in an object. It is used in the assessment of specific skills in a learning activity that could be divided into a series of clearly defined specific actions. It can be used to evaluate development of social behavior Consider the following examples:

\section{Evaluating Pupils' Social Skills}

1. Plays with other children

2. Shares toys with other children

3. Grabs everything to himself/herself

4. Likes to play alone

5. Smiles very often at other children

Yes/No
Yes/No
Yes/No
Yes/No
Yes/No

5. Rating Scale: The rating scale is like the checklist. The difference lies in the fact that while the checklist is used to indicate whether or not a trait is present, the rating scale is used to show the degree, from the lowest to the highest, to which the trait or quality is present. For example a checklist may indicate the presence or absence of shyness while the rating scale may indicate whether the shyness is present to a very small extent, medium or average extent, large extent and very large extent. Usually the scale is allocated figures (1-5) corresponding to the rating from very small extent (1) to a very large extent (5).

6. The Sociometric Technique The school has the obligation of developing all aspects of the child: physical, social, intellectual, and moral adjustments. A child's social acceptability could be describes as the extent to which he/she is acceptable to his/her mates as leader or a member of a working, dancing, playing, or study group. Peers have a way of assessing one another's capabilities or social behavior. Their opinions could be used to assess individual social acceptability within a given group. The sociometric techniques are used to measure this aspect. It may be defined as a process of collecting and analyzing data on "choice" within a specified group. It is a process of measuring individual social acceptability as well as a social structure or interaction pattern of given group.

Pupils could be given forms containing the following statements to

complete:

1. I would like the following to be in my Project Group......

2. I would like the following to be in my Games Group.....

3. I would like the following to be in my Study Group.....

\section{Conclusion}

The paper could only touch on the periphery of some aspects of the evaluation process in the educational setting. It pointed out that evaluation is an essential aspect of the instructional process which is used to gather information for making judgments and making decisions on educational matters. Evaluation provides useful information for the improvement of teaching strategies, for the improvement of the curriculum and, above all, for the improvement of learning.

Effective evaluation is possible only if the objectives for the evaluation are clearly stated and the appropriate techniques are applied for information gathering. It should be noted always that since learning at the Primary level and at any level of education for that matter, focuses on all-round development of the learner, it is also important that our evaluation should focus on the three domains: Cognitive, Affective and Psychomotor. It is important for the Teacher, the Head Teacher and the Inspectors of School to regard one another as professional colleagues and work together for the improvement of education. 


\section{References}

Ismaila, U. Y. (2003) Evaluating Learning Outcomes in Schools: Some strategies And

Processes For Effective Implementation. A paper presented at the Train-the-trainer workshop on Guidance and Counseling for Primary Education organized by Katsina State Education Trust Fund, Katsina.

Iwuji, V.B.C. (1990) Measurement and Evaluation for Effective Teaching andLearning. Onitsha, Summer Educational Publishers.

Lagos State Primary Education Board (1994). Progress Report for Primary Schools Nigeria, Macmillan.

Makama,, O.M. (2005) Programme Evaluation in Education. Anambra, Pacific Publishers.

Ohuche, K.O. (1990) Basic Measurement and Evaluation. Onisha, Africana Fep.Publishers.

Okoro, O.M. (1991) Programme Evaluation in Education. Anambra Pacific Publisher. 